\title{
Luke Haywood*
}

\section{Watch your Workers Win. Changing Job Demands and HRM Responses ${ }^{* *}$}

This paper considers how the demand for non-material aspects of jobs evolves over changing wealth levels and how firms may want to react. We first consider the importance of non-material job aspects in general before turning to two specific human resource practices: flexible working hour arrangements and employer pension provision.

In order to estimate the effect of wealth on job preferences without confounding it with the potential effect of job preferences on wealth due to earnings differentials, we focus on non-labour income (e.g. lottery winnings). We test how it affects workers' preferences using an approach based on duration data.

Key words: job satisfaction, wealth, HRM, job mobility, turnover (JEL: J28, J32, J63, M52, M54)

* Luke Haywood, Paris School of Economics \& Université de Paris 1, Panthéon-Sorbonne. E-mail: haywood@pse.ens.fr.

** For helpful comments and suggestions I would like to thank Andrew Clark, Jean-Marc Robin, Katherine Cuff, Fabrice Gilles, two anonymous reviewers and seminar participants in Paris (SIMA), Dubrovnik ("Job Satisfaction Revisited"), Rome (AEA conference), Angers (JMA) and Marseille (LGAV).

Article received: February 24, 2010

Revised version accepted after double blind review: December 13, 2010. 
When firms decide on workers' wages, an important factor is the risk that too low wages may induce workers to leave. Many factors may determine the value of a particular job to an individual. A worker who has a higher wage, enjoys the work she does, has friendly colleagues and flexible working hours has been found to be less likely to quit. However, the relative weights of different aspects of employment may vary over time and circumstances. For example, material aspects may become more important when a worker's spouse loses their job and becomes dependent. Similarly, the number of children may have an influence on the preferences for certain job characteristics. With the importance of worker turnover in mind, we may thus be interested in estimating the effect of different influences on job leaving behaviour. Most changes in life circumstances are related in complicated ways to individual behaviour (couples may choose to have a child also as a function of their expectations of future labour market outcomes), making estimation of the impact of such changes on preferences for job characteristics difficult.

This paper tests the impact of changes in wealth levels on preferences over job characteristics. The empirical strategy uses information on windfall gains (mainly from lottery winnings and inheritances) as an instrument for wealth changes. These windfalls are expected not to be caused by labour market behaviour and thus provide an original source of identification for the effect of wealth on job preferences of workers.

Section one places our research question within the framework of literature on turnover and job search.

Section two presents a measure of non-material aspects of a job based on subjective survey data. The single-item measure of job satisfaction for work "in itself" measures a particular dimension of job satisfaction different from monetary compensation.

Section three reviews the British household panel data that is used, covering job durations with information on job characteristics as well as workers' windfall gains.

Section four first reviews descriptive evidence on job leaving rates across different groups that appears suggestive of a role for wealth shocks in influencing job preferences. The empirical model to explain job leaving as a function of windfalls and job satisfaction is then presented and estimated. Results confirming an influence of wealth on job preferences are discussed.

Section five considers which management practices may become more important as workers become more wealthy: what might managers do to avoid turnover by workers who become less dependent on the material payoffs of their job? The impact of working time arrangements and employer pension fund contributions on changing job leaving is tested.

\section{Determinants of worker turnover}

The current paper considers influences on voluntary turnover decisions by workers. There is a considerable literature on voluntary turnover, and in particular on individuals' motivations for turnover. The classic analysis in the management field by March and Simon (1958) distinguishes two factors influencing workers' mobility decisions: perceived desirability of an individual's current employment and perceived ease of movement away from current employment. Our research question can be framed in 
these terms as follows: When ease of movement changes as a result of a wealth shock - e.g. because individuals have the resources to sustain a transitional search period without earnings - does perceived desirability become more important?

Turnover research has focused on various dimensions of individual differences which influence turnover decisions. Personality, gender and industrial sector have for example been found to be of importance for job leaving (Barrick \& Mount, 1996). Wealth differences appear to constitute an important difference across individuals. In fact, whilst certain personality traits (such as the so-called Big 5) are arguably intrinsic, others may be affected by wealth shocks - e.g. we may expect rising self-confidence. To the extent that self-confidence is important for job leaving (Barrick \& Zimmerman, 2005), the impact of wealth may pass via self-confidence.

This article is related to a research agenda instigated by Lee and Mitchell (1994)'s "Unfolding Model" which proposes five determinants of turnover decisions: shocks, scripts (pre-existing leaving plans), image violations (broken expectations), job satisfaction and job search. These are said to combine to generate four different turnover path types. In the first path, a shock triggers a pre-existing plan. If we take wealth as the shock, it may be hypothesized that workers with lower job satisfaction may be more likely to have pre-existing plans to leave. In path two, shocks lead workers to reconsider their situation. They then leave only after a period of deliberation. The value of duration models is to not restrict the period over which we allow the shock to operate. Instead of looking at the impact of a wealth shock for turnover decisions in the following month or year, we consider the impact for the whole length of tenure. The hypothesis of this paper is that a re-evaluation of a worker's situation after a wealth shock will include, in particular, their level of job satisfaction. Compared with path two, path three concerns those individuals that leave for another job - i.e. after assessing alternative options. To the extent that we cover voluntary turnover both to unemployment and to alternative employment, we cover this type also. Path four is defined as a path where lower job satisfaction independent of the shock is the "precipitating" factor of movement.

The idea of the current work is to test whether by changing the relative importance of monetary and non-monetary job components, wealth shocks lead to a reevaluation of jobs' desirability in terms of job satisfaction. Thus wealth and job satisfaction interact to determine turnover outcomes. If this is the case, this appears consistent with paths one to three of the Unfolding Model - which we will not attempt to distinguish in the empirical part. The approach resembles that of a study by Holtom et al. (2006) ${ }^{1}$ who compare the degree of job embeddedness (a concept related to individuals' attitude towards their employer) compared across stayers and leavers, distinguishing between shock leavers and non-shock leavers. The duration data model that we use contrasts durations of individuals before and after receiving a shock and over different levels of job satisfaction. In a recent paper, Lee et al. (2008) show that job satisfaction has a strong impact on voluntary job leaving for workers in a variety of situations: Workers leaving to search for a new job; workers leaving to accept a solicited or unsolicited job offer as well as workers leaving for family reasons. Testing the rela- 
tive importance of "push" versus "pull" factors, they also find that unemployment is not a significant factor in voluntary job leaving decisions.

In economics, turnover has mainly been considered under the prism of job search theory, in which the informational frictions in the labour market are modelled using a stochastic job offer arrival rate which individuals can sometimes influence by adjusting their search effort. One of the results of simple job search models is that workers' best strategy for on-the-job search is simply to compare the utility of their current job to the level of utility in an alternative job. Thus a many-period game with potentially complex dynamics has a simple static solution, this is the insight famously used in Burdett and Mortensen (1998). ${ }^{2}$

A requirement for this kind of enlightened job choice is that individuals are aware of the different levels of utility associated with a job (the salary, but also the nonmonetary component) - for their current job and for any job offers. To test whether this is the case, Gielen (2008) looks at workers' job-to-job transitions using the same data analysed here and finds that only a limited amount of movements can be explained by information-gathering, whilst many more moves are consistent with informed workers choosing jobs with higher levels of utility. Informed transitions provide the basis for our treatment here. It is assumed that jobs consist of a monetary and a non-monetary component - and that the utility of the non-monetary component is adequately measured by answers relating to “job satisfaction for work in itself”. We now turn to this two-dimensional measure of jobs and consider whether such a simple characterisation of individuals' appreciation of working conditions can be justified.

\section{Job satisfaction: domains and measurement}

Job satisfaction is a multi-facetted concept for which psychologists have elaborated sophisticated models. This paper investigates how a wealth shock may change the relative importance of non-monetary aspects of jobs. Non-monetary job aspects are not always easy to observe. As a measure for non-monetary aspects of the job we require something that workers evaluate independently of their wages. We might consider subjective job satisfaction, i.e. answers to the question "How satisfied are you with your job?" However, if we assume that evaluations of overall job satisfaction include both job satisfaction with pay as well as job satisfaction with non-monetary aspects of a job, it is clear that this single-item measure of overall job satisfaction cannot be used. We require a measure only of the non-monetary element of job satisfaction. However, it is clear that we cannot test the potential independence by testing the correlation between a measure of nonmonetary job characteristics with wages: If it is the case that wealth influences the demand for non-monetary job characteristics, incomes will also influence this demand by changing wealth levels. Then we would suspect a correlation between non-monetary job satisfaction and wages in the absence of any problem in our measure of non-monetary job aspects.

2 It is only when more sophisticated considerations such as using offers as bargaining chips (see e.g. Postel-Vinay \& Robin, 2002) are taken into account that more complicated dynamic strategies are generated. 
It may be thought that our requirements for a measure of non-monetary job characteristics independent of wage are difficult to be met for another reason: Tenets of perfect markets may argue that wages should be expected to compensate for differences in the quality of non-monetary job aspects. This would lead to pay levels being set according to job dis-amenities as Adam Smith already predicted (the classic modern exposition is by Rosen, 1986). However, in line with the vast literature on job search, we only need to acknowledge the lack of perfect information on the job market in order to avoid the prediction of a deterministic relationship of job amenities and wages (see in particular Hwang et al. 1998). As long as there is some stochastic variation in the relationship between our measure of job characteristics and wages - which job search models would, for example, predict - we can use this to identify the effect we are interested in.

Table 1: Measures of job satisfaction

\begin{tabular}{l|c|c|c|c}
\hline & Mean & Standard Dev. & Min & Max \\
\hline $\begin{array}{l}\text { Job Satisfaction } \\
\text { overall }\end{array}$ & 5.182 & 1.363 & 1 & 7 \\
\hline $\begin{array}{l}\text { Satisfaction with } \\
\text { pay }\end{array}$ & 4.829 & 1.794 & 1 & 7 \\
\hline $\begin{array}{l}\text { Satisfaction with } \\
\text { job security }\end{array}$ & 5.315 & 1.552 & 1 & 7 \\
\hline $\begin{array}{l}\text { Satisfaction with } \\
\text { work in itself }\end{array}$ & 5.289 & 1.371 & 1 & 7 \\
\hline $\begin{array}{l}\text { Satisfaction with } \\
\text { working hours }\end{array}$ & 5.088 & 1.427 & 1 & 7 \\
\hline
\end{tabular}

Note: The precise question was: "I'm going to read out a list of various aspects of jobs, and after each one l'd like you to tell me from this card which number best describes how satisfied or dissatisfied you are with that particular aspect of your own present job."

The scale (on the card) varies from "1- Not satisfied" over "4-Not satisfied, not dissatisfied" to "7-Completely satisfied".

The measure that appears to fit rather well the requirements is "job satisfaction for work in itself": clearly directed at a subjective evaluation of intrinsic characteristics of the workplace whilst at the same time clearly distinct from financial rewards ${ }^{3}$. Thus the present study uses this one dimension of job satisfaction (job satisfaction for work “in itself') as a measure for workers' appreciation of all nonmonetary aspects of a job. The other element assumed to be important in the eyes of workers is the wage. These two components entirely describe a workplace. ${ }^{4}$ In the large panel data used for this

3 It may serve as a useful instrument even if this measure does not give a complete characterisation of relevant job characteristics - it may for example abstract from contextual or relational aspects (e.g. relationships with superiors etc.). Furthermore, we may be concerned about relying on a single-item measure. Considering job satisfaction overall - i.e. not the specific domain satisfaction we use - Wanous et al. (1997) discuss to what extent the summary single-item measure is correlated to more sophisticated measurements of job satisfaction and conclude on an optimistic note.

4 Given that numerous sector and individual dummies are added in the regression analysis, the identifying assumptions in the empirical part are in fact less restrictive. 
research, several subjective measures of domain job satisfaction are available: In particular, table 1 gives the different measures of subjective job satisfaction for the period under consideration we have information on. We do not need to make assumptions about the links between objective job characteristics (other than wages) and the subjective evaluation of non-monetary job satisfaction. However, in this article, job quality, job characteristics, job satisfaction and working conditions are used interchangeably: our subjective measure is considered to be a sufficiently good instrument for some objective characteristics. We do not require that individuals have the same attitudes towards these characteristics - the same work may be viewed as in itself very satisfying by one person and not by another. In order to test whether wealth shocks lead to more importance being given to these considerations we need attitudes to be stable across time however. Whilst the subjective nature of the instrument may mean it varies not just across individuals but over time, numerous studies have confirmed the strong correlations between this subjective measure and later objective outcomes: the fact that job satisfaction predicts future job turnover rates is an illustration of the possibilities afforded by this measure and ensures a degree of stability over time. Early papers to note this fact are Hamermesh (1977) and Freeman (1978). Using subjective data on job satisfaction, Clark (2001) shows that data on job satisfaction predict quitting behaviour in the UK, and that it can be used to establish "what matters most in a job". Using the same data used in the present study he finds that of the different domain satisfaction measures of table 1 , job security and pay are the most important, followed by work in itself and hours of work. Overall job satisfaction is found to be a good predictor of future separations. Clark et al. (1998) find that dissatisfied German workers, too, are more likely to quit. In what follows we will use job satisfaction, job quality and working conditions interchangeably for only one aspect of job satisfaction - our measure of the non-material aspects of a job, i.e. job satisfaction for work "in itself'.

\section{The British Household Panel Survey}

We use the British Household Panel Survey, a panel of around 10,000 persons broadly representative of the British population covered over 17 yearly waves from 1991 onwards.

The main variables of interest are windfalls, subjective job satisfaction, job duration and wages, as well as demographic and firm control variables. Job market data falls into two categories: In every wave, workers are first asked about the characteristics of their current job, including their subjective evaluation of working conditions and detailed information on earnings. Second, they are asked about transitions within their firm (e.g. promotions) and across firms (changes of employer or labour market status) in the preceding year. Our sample thus combines information on wages, working conditions and job durations.

\subsection{The sample}

We focus on employed individuals for whom we have multiple observations who encounter at least one windfall during the panel observation period. For this subsample we have information on 10386 completed job spells from 3488 workers. Given the 
specific factors involved in choosing retirement, the sample is restricted to those aged between 16 and 50, with a sample average age of 34 years. The sample is $49 \%$ female, $51 \%$ are married and the average level of education is around 12 years. $2 \%$ of the male and $30 \%$ of the female sample work part time.

\subsection{Windfalls}

Windfall earnings are recorded from lottery winnings, gambling gains, inheritances, life insurance and accident payouts and money received as a result of building society conversion. ${ }^{5}$ The assumption made here is that these windfalls were not anticipated such that no behavioural changes can be made prior to the windfall. We have no information on the exact date of the windfall, and assume that the windfall occurred at the beginning of an observation period (between two waves). If a worker reports having received a windfall in the preceding period and also reports job mobility, we thus assume that the windfall occurred before the mobility decision. This assumption ensures that windfalls are not anticipated as a result of our recording scheme.

Table 2: Size of windfalls received

\begin{tabular}{l|c|c|c|c|c}
\hline & Inherit. & Lottery & Life ins. & Accident ins. & Total \\
\hline 1-1000 pounds & 98 & 2255 & 50 & 41 & 2695 \\
\hline $1000-5000$ pounds & 158 & 78 & 198 & 148 & 627 \\
\hline $5000-10000$ pounds & 79 & 8 & 32 & 23 & 149 \\
\hline $10000-50000$ pounds & 115 & 2 & 42 & 11 & 183 \\
\hline $50000+$ pounds & 35 & 1 & 5 & 1 & 49 \\
\hline
\end{tabular}

Note: For one year (wave 5) only aggregated data are available - included in total.

Table 3: Size of windfalls received as percent of annual income

\begin{tabular}{l|c|c|c|c|c}
\hline & Inherit. & Lottery & Life ins. & Accident ins. & Total \\
\hline $1-10 \%$ of annual income & 141 & 2,264 & 78 & 61 & 2,788 \\
\hline $10-50 \%$ of annual income & 153 & 69 & 184 & 122 & 578 \\
\hline $50-100 \%$ of annual income & 67 & 8 & 29 & 29 & 139 \\
\hline $100+\%$ of annual income & 124 & 3 & 36 & 12 & 198 \\
\hline
\end{tabular}

Note: For one year (wave 5) only aggregated data are available - included in total.

Consider the worker in figure 1: In September 2002 she reports having received a windfall in the previous year. Since the timing of this windfall is unclear, we do not know whether it occurred before or after January 2002 - i.e. before or after the job

5 This is somewhat of a British peculiarity: After the financial Big Bang of the early 1990s a number of building societies (basically consumer cooperatives) demutualised to become banks. In the process, considerable windfalls were distributed to customers. The deregulation of the banking sector was a sudden policy change making it very likely that these earnings qualify as windfalls. There was some speculative behaviour (joining building societies in the hope of demutualisation), but often clauses were enacted to avoid payouts to recently joined-up members. 
change. We assume that the windfall occurred prior to January 2002. To the extent that windfalls are received later, any effects of windfalls will occur in later waves - i.e. we can test for lagged effects in later waves.

Figure 1: Example of timeline of survey interviews and events

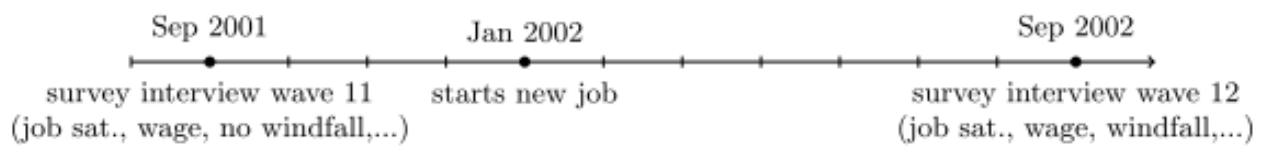

Figure 2: Example of timeline of survey interviews and events

Sep 2001,
(job sat., wage, no windfall,...)

We focus on respondents who record some windfall earnings over the period of the panel. The majority of windfalls involves small amounts, with a large spike of $f 100^{6}$ and a majority of this results from lottery winnings, gambling and inheritances. Whereas lottery winnings tend to be small, with a recorded mean of $f, 150$, accident ( $f$ $237)$ and life insurance $(£, 584)$, but especially inheritances $(£, 2294)$ are larger, as table 2 shows. Whilst most windfalls appear fairly small compared to earnings, table 4 shows that $5 \%$ of windfalls exceed annual earnings of workers.

\subsection{Job duration data}

The measure of job duration used here is firm tenure, such that within-firm mobility does not constitute job leaving. The advantage of considering total duration of a worker with a particular firm rather than in a particular job position is that within-firm mobility includes promotions which are most certainly endogenous to workers' behavior. $^{7}$ As a result, there may be some fluctuation in the wages and working conditions within a job (as workers change jobs within a firm). This appears acceptable given our estimation strategy (focusing on differential quitting rates) if we use information on the last available wage and working conditions before a worker left a job. In the rest of the paper we refer to movements of workers away from employment at a certain firm as job leaving.

As an example, consider the timeline of a worker depicted in figure 1. She is observed in the survey interview at wave 11 as being employed at a certain employer and provides information on job satisfaction, working conditions etc. In wave 12 she reports having changed employment in the previous year and provides information on working conditions and earnings at her new employer. Since the worker provides the

6 All monetary values provided are deflated to their values in 2000 . For building society conversion earnings we have no information on windfall size - payouts here varied considerably.

7 In practice, results did not seem very sensitive to using alternative definitions of spells as job or firm tenure. 
exact end date of the job, we have precise information on job duration. For the job up to January 2002 we assume the covariates provided in September 2001 apply, for the job from January 2002 onwards we assume it is characterized by wage and working conditions reported in wave 12 (first interview reporting the new job). Thus we only assume that working conditions remain constant from the time of the last interview until movement away from the job. This also means that we cannot use spells for which we have no corresponding survey information - this is the case of the worker in figure 2 for whom we have no information on the job between January and April 2002.

\subsection{Stock sampling}

In our estimation we must control for the fact that we are more likely to have all the information we require for spells that last longer. In the example outlined in figure 2, whilst the job spell from April 2002 onwards is observed, the spell from January to April 2002 is not observed. We condition on job duration (tenure) at date of entry into the sample to control for the likelihood of observing an observation - the likelihood of a job lasting until the interview date.

We exclude individuals for whom we only have one spell in order to increase the efficiency of estimation. ${ }^{8}$ We have on average 2.8 job observations per individual.

\subsection{Censoring}

As in most duration data sets, we do not observe the spell end date for all individuals. The typical assumption made is that of random censoring, i.e. that those individuals who are censored do not have different characteristics than those for whom we observe spell end dates.

Table 4: Destinations of job leavers

\begin{tabular}{l|c|c}
\hline & number of spells & percent \\
\hline to new job & 1985 & 16.47 \\
\hline to unemployment & 1107 & 9.19 \\
\hline to university & 83 & 0.69 \\
\hline retirement & 24 & 0.20 \\
\hline family-related & 229 & 1.90 \\
\hline health-related & 170 & 1.41 \\
\hline other & 1512 & 12.55 \\
\hline censored & 6940 & 57.59 \\
\hline total & 12050 & 100 \\
\hline
\end{tabular}

Censoring may be a particular issue if we have no end dates for the longest spells which may be ongoing. In our data this concerns very few spells as there is considerable mobility in the British labour market over the period studied. Many more spells are censored as individuals drop out of the panel for unknown reasons. For these we assume random censoring.

8 Van den Berg (2001) shows that shared frailty models (random effects models with several observations per individual) offer considerable advantages over models with only one observation per individual. 


\subsection{Transitions}

All labour market transitions may be affected by the change in wealth. In particular, we may wish to distinguish transitions within the labour market from transitions to non-participation. We observe voluntary transitions to another job, to university, retirements and jobs ending for family reasons as well as involuntary transitions redundancies, sacking or ending of part-time jobs. In order to keep sample sizes reasonable, we do not differentiate between different transitions in a competing risk framework. Rather, we focus on all voluntary transitions - excluding all different types of dismissal, redundancy and retirement.

\subsection{Job Satisfaction}

The measure used for non-monetary job characteristics is the answer to the question "How satisfied are you with your job in itself?", with potential answers ranging from " 1 - not at all satisfied" to " 7 - completely satisfied". The presence of other questions relating specifically to satisfaction with financial rewards should reassure us that the dimension of job quality measured here relates exclusively to factors other than remuneration, as the empirical strategy requires. Table 1 provides information about different measures of job satisfaction.

\section{Empirical Analysis}

Descriptive evidence of the impact of wealth shocks on transition behaviour is presented in figures 3 and 4 which give the smoothed hazard rate and the survival rates by receipt of a large windfall (defined as a windfall greater than $f^{2000)}$ and by job satisfaction (high job satisfaction defined as "nearly completely" or "completely satisfied" workers), focussing on the first 100 months of a job.

Figure 3: Moving to another job: by windfall and job satisfaction

Large windfall here defined as a windfall greater than $£ 2,000$

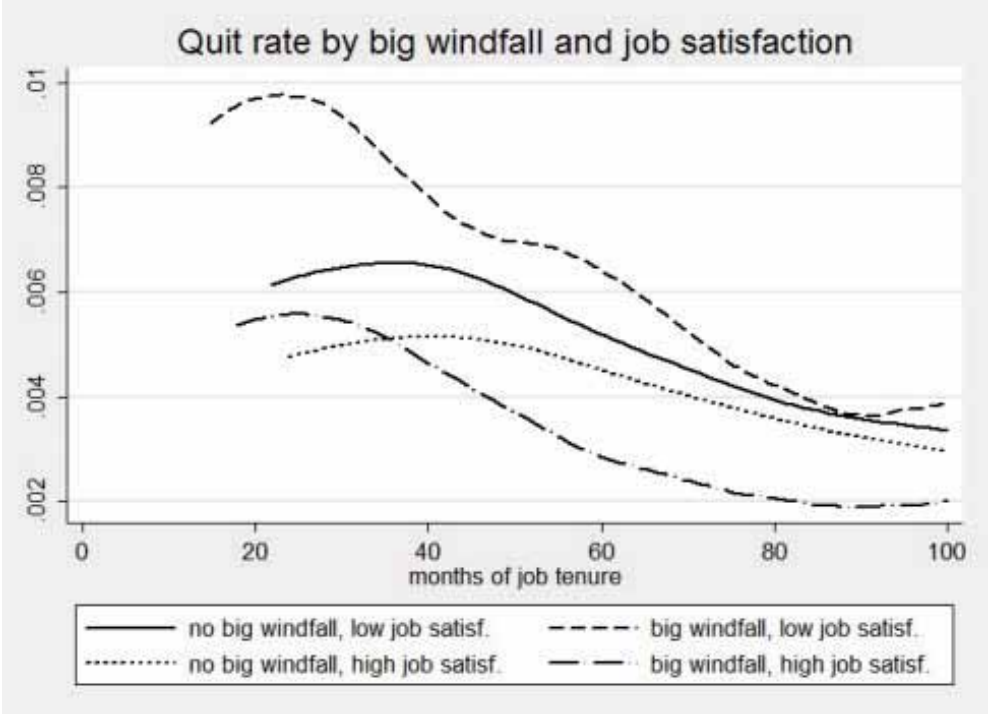


We find that quit rates are highest for the group of workers with low job satisfaction and windfalls (maybe a call centre lottery winner) and lowest (over most of the job duration) for workers with high job satisfaction and windfalls (e.g. an artist lottery winner who can continue her low-paid job). This variation in the impact of wealth shocks on mobility decisions over different levels of job satisfaction provides a starting point for a more rigorous causal analysis.

Figure 4: Staying in a job: by windfall and job satisfaction

Large windfall here defined as a windfall greater than $£, 2,000$

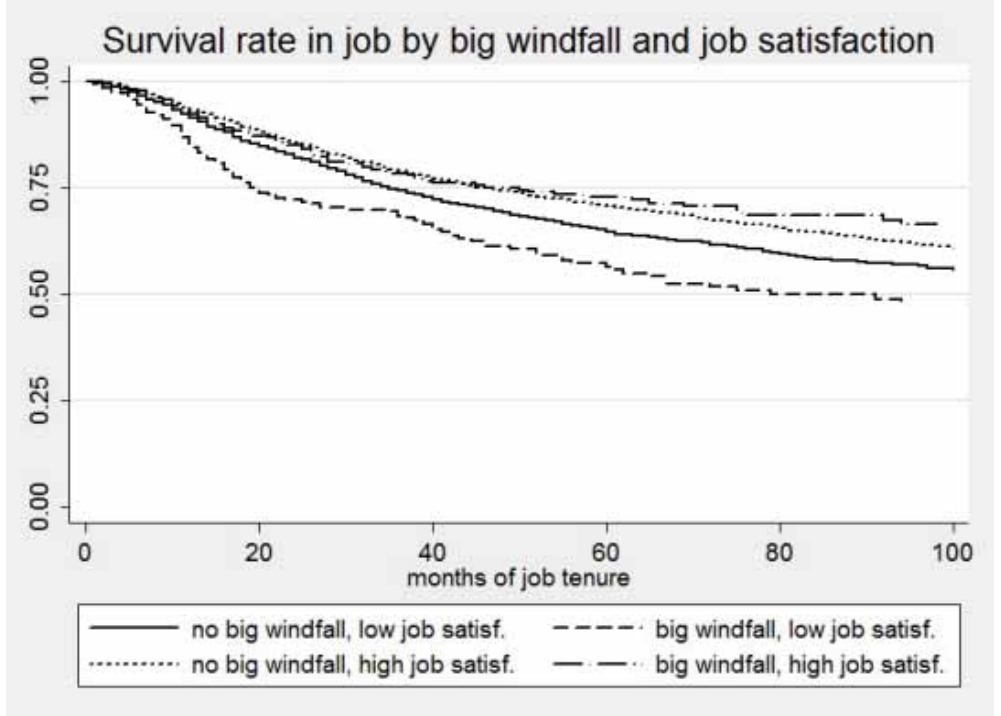

\subsection{The Cox Proportional Hazard model}

In order to map the factors influencing job leaving, we focus on the hazard rate, a measure of the duration distribution. The hazard at time $t$ is the probability of job leaving conditional on having stayed in a job spell $s$ up until $t$. Because it is thought that for many dynamic processes, the duration $t$ is itself a factor determining the rate of exit out of a state (here, an employment), researchers typically distinguish between a baseline hazard $\theta_{0}(t)$ depending on duration and a systemic part of the hazard $\theta_{1}(x)$ which gives the influence of the covariates. A simplifying assumption many researchers make is that the two parts are multiplicatively separable, generating the proportional hazard model. The implications of the resulting formulation (1) is that the covariates - amongst others here income and job satisfaction - have a proportionally constant influence on the hazard rate over different job durations.

In order to take into account potential differences across individuals that are not covered by observables $\underline{x}$, an individual effect for unobserved heterogeneity $\eta_{i(s)}$ is added in (1).

$$
\theta_{s}\left(t_{s} \mid \underline{x}_{s}\right)=\theta_{0}\left(t_{s}\right) \exp \left(\underline{x}_{s}^{\prime} \underline{\beta}+\eta_{i(s)}\right)
$$




$$
\begin{gathered}
\text { Or, defining } \xi_{i(s)}=\exp \left(\eta_{i(s)}\right): \\
\theta_{s}\left(t_{s} \mid \underline{x}_{s}\right)=\theta_{0}\left(t_{s}\right) \theta_{1}\left(\underline{x}_{s}\right) \xi_{i(s)}
\end{gathered}
$$

The Cox Proportional hazard model (CPH) allows for many types of different functions for duration dependence $\theta_{0}(t)$ - in fact any multiplicative time-dependent baseline hazard rates are acceptable. The procedure is semi-parametric in the sense that the baseline (unobserved) hazard $\left(\boldsymbol{\theta}_{0}\right.$ in (1)) is not estimated and the partial likelihood estimates of the coefficients $(\underline{B})$ are nonetheless consistent. The intuition for the partial likelihood is - for a spell $s$ - to use the conditional probability that spell $s$ ends, given risk set $R^{s}$ defined as the set of spells ending at or after $s$. Due to the proportionality assumption, the baseline hazard - assumed to be the same for all individuals - drops out.

Thus we write the partial likelihood conditional on the individual effects as:

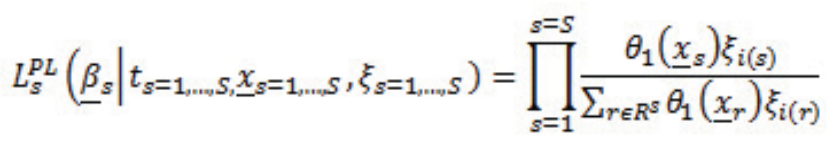

The $\mathrm{CPH}$ model buys semiparametric identification at the cost of efficiency: Only the ordering of job durations influences the likelihood, not the precise timing - so not all information is used for estimation.

For $\xi$ we here follow a parametric route and assume $\underset{\xi}{\rightarrow}$ Gamma. The gamma distribution is not only a flexible distribution but it has also been shown that very general random processes can be well approximated by this distribution (Abbring \& van den Berg, 2007). Multiple observations per individual somewhat weaken the strong assumptions on orthogonality between random effects and other explanatory variables (van den Berg, 2001). For the individual likelihood contribution this implies integrating out the individual effect:

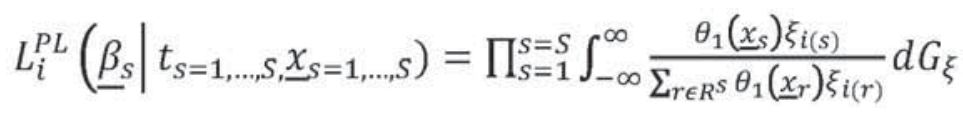

\subsection{Changing importance of job satisfaction}

Our empirical analysis looks into the evolution of two key job characteristics hypothesized to influence job leaving decisions: the wage and job satisfaction for work in itself. In line with previous research, both are found to have a strongly significant impact on individuals' job mobility choices. The regressions control for individual characteristics (age (non-linearly), education (non-linearly), family situation (4 dummies)), objective working conditions (part-time (dummy), working hours), as well as 13 sector dummies thought to be potentially related to working conditions. The dependent variable in regressions is the hazard rate, i.e. the probability of job leaving at any point in time. Using the Cox limited information structure, the models allow for unspecified types of duration dependency (subject to the proportional hazard assumption). Fur- 
thermore, gamma-distributed shared random effects are included in the model and unobserved heterogeneity in job leaving is found to be significant.

In line with the initial hypothesis, it is found that the impact of windfalls on job leaving depends importantly on the level of job satisfaction, i.e. that the interaction effect is negative, such that the coefficient on job satisfaction becomes larger in absolute terms after a windfall. In table 5 we find that the interaction is in fact non-linear in the windfall with higher windfalls showing over-proportionally more impact on the size of the coefficient of job satisfaction.

Table 5: Job leaving as a function of wage and job satisfaction

Model 1 adds log windfalls and interactions in levels; model 2 adds windfalls as a percentage of annual income and interactions. See the footnote for the numerous controls included in the regressions. Dependent variable: hazard rate of voluntary job leaving

\begin{tabular}{|c|c|c|}
\hline & $\begin{array}{c}\text { Model } 1 \\
\underline{\underline{B}} \text { (robust s.e.) }\end{array}$ & $\begin{array}{c}\text { Model } 2 \\
\underline{\underline{B} \text { (robust s.e.) }}\end{array}$ \\
\hline Log Wage & $\begin{array}{c}-0.585^{\star \star *} \\
(0.055)\end{array}$ & $\begin{array}{c}-0.488^{* * *} \\
(0.041)\end{array}$ \\
\hline Job Satisfaction & $\begin{array}{c}-0.099^{* * *} \\
(0.017)\end{array}$ & $\begin{array}{c}-0.089^{* * *} \\
(0.021)\end{array}$ \\
\hline Log Windfall (LWF) & $\begin{array}{l}-0.242 \\
(0.321) \\
\end{array}$ & \\
\hline Log Windfall squared (LWF2) & $\begin{array}{c}0.042 \\
(0.039) \\
\end{array}$ & \\
\hline (Job Satisf * LWF) Interaction & $\begin{array}{l}0.030^{* *} \\
(0.013)\end{array}$ & \\
\hline (Job Satisf * LWF2) Interaction & $\begin{array}{c}-0.004^{* * *} \\
(0.001)\end{array}$ & \\
\hline (Log Wage * LWF) Interaction & $\begin{array}{c}0.009 \\
(0.034) \\
\end{array}$ & \\
\hline (Log Wage * LWF2) Interaction & $\begin{array}{l}-0.001 \\
(0.004) \\
\end{array}$ & \\
\hline Windfall as \% income p.a. (WF/W) & & $\begin{array}{c}0.006 \\
(0.010) \\
\end{array}$ \\
\hline (Job Satisf * WF/W) Interaction & & $\begin{array}{l}-0.004^{\star \star *} \\
(0.001)\end{array}$ \\
\hline (Log Wage * WF/W) Interaction & & $\begin{array}{c}0.002 \\
(0.001)\end{array}$ \\
\hline Log Pseudolikelihood & -6013.41 & -6026.59 \\
\hline
\end{tabular}

Controls: age,agez,education,education2, 13 industry dummies, 4 family situation dummies, working hours, parttime dummy; Sample size: N = 3488; _ _ S = 10386; Significance levels: $10 \%\left({ }^{*}\right), 5 \%\left({ }^{* *}\right), 1 \%\left({ }^{(* *}\right)$ 
To gain an understanding of size and significance of the effects over a range of windfalls and keeping over covariates constant we do a simulation ${ }^{9}$ the results of which are presented in figure 5. We investigate the difference in job leaving of a one-point increase in job satisfaction (from level 6 to 7) for a 35-year old never married person working full-time 35 hours in the manufacturing sector earning $£, 12,000$ yearly. We find that the marginal effect starts to become significantly different from the baseline for windfall values of around $£, 1000$, changing quite significantly for larger windfalls. For windfalls above $£, 100,000$ the precision of the estimates is strongly reduced as we face small samples.

\section{Figure 5: Marginal effect of job satisfaction over windfall}

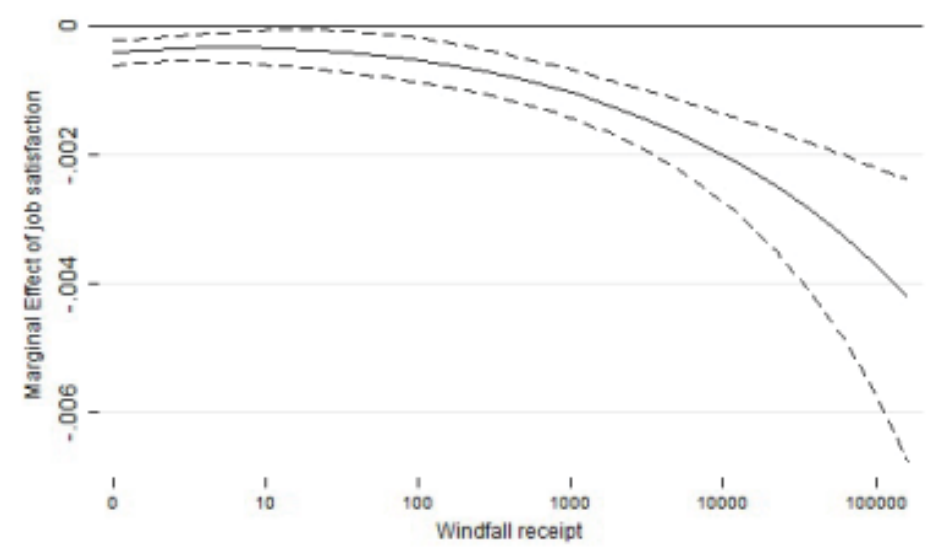

\section{Human Resource Management responses}

Employee turnover may carry considerable costs for. Whilst estimates of the precise costs vary a great deal, ${ }^{10}$ one aim of human resource practices such as flexible working hours or pension contributions may be employee retention (Houseman (2001)). In the previous section, subjective job satisfaction for work "in itself" was used as a measure of working conditions in a firm. Can we go beyond that and find objective characteristics that might become more important to workers as a result of the wealth shock? First, model (2) in table 5 indicates that the impact of a wealth shock depends importantly on an employee's level of earnings. In fact the model achieves a better fit if we express windfalls as a percentage of annual earnings. Thus changing job preferences are clearly more relevant for less well-paid workers. Put another way, firms can still retain workers who care more about the intrinsic job characteristics by paying higher wages.

What else might managers do? We explore two particular practices that have received some attention in the human resource literature: flexible working arrangements and whether the employer participates in a private pension scheme.

Ai and Norton (2003) note that the interaction effect in non-linear models is not the marginal effect we would like to use for interpretation.

10 Holtom et al. (2008) cite a range from less than one times a worker's monthly income to more than two yearly incomes. 


\subsection{Latent preferences for flexible working hours}

Most types of employment contract stipulate not only a given number of hours, but also the specific schedule when these hours must be worked. This second constraint might be particularly costly for individuals who have important family commitments, and in particular, childcare obligations. How might demand for flexible working hours be affected by changing wealth levels?

On the one hand, increased levels of wealth should increase demand for leisure activities, some of which may be difficult to reschedule. More generally, to the extent that flexible working hours are an immaterial job characteristic we might expect the relative weight of flexibility to have increased after a wealth shock.

On the other hand, the impact of these "scheduling costs" (Wilson, 1989) may be reduced when childcare provision can be purchased by families. This might suggest a decrease in the relative importance of flexible working hours to workers after a wealth shock.

We use a series of questions related to specific working hour arrangements and generate a dummy for flexible working hours. Jobs for which individuals declare that employers run a scheme of "flexitime", "annualised hours", "job share", "nine day fortnight" or "zero hours contract" are all classified as flexible working arrangements. In practice, $85 \%$ of the flexible working hours arrangement concerned flexitime. Whilst flexitime arrangements vary, workers are in general required to work at "core" times and free to schedule their working hours around these - subject to a total number of hours being worked in a given period.

Table 6: Job leaving as a function of wage, windfalls, flexible working hours and an interaction term.

The first two columns on the left compare mothers to childless women and men; the middle two columns compare coefficients for men and women and the two columns on the right compare parents to individuals without dependent children. See the footnote for the numerous controls included in the regressions. Dependent variable: hazard rate of voluntary job leaving

\begin{tabular}{|c|c|c|c|c|c|c|}
\hline & $\begin{array}{l}\text { Mothers } \\
\hat{\beta}\end{array}$ & $\begin{array}{l}\text { Childless or Men } \\
\hat{\beta}\end{array}$ & $\begin{array}{l}\text { Women } \\
\hat{\beta}\end{array}$ & $\begin{array}{l}\text { Men } \\
\hat{\beta}\end{array}$ & $\begin{array}{l}\text { Childless } \\
\hat{\beta}\end{array}$ & $\begin{array}{l}\text { Parents } \\
\hat{\beta}\end{array}$ \\
\hline Log Wage & $\begin{array}{l}-0.561^{\text {******* }} \\
(0.198)\end{array}$ & $\begin{array}{l}-0.691^{* * * *} \\
(0.138)\end{array}$ & $\begin{array}{l}-0.711^{\text {***** }} \\
(0.186)\end{array}$ & $\begin{array}{l}-0.616^{* * * *} \\
(0.173)\end{array}$ & $\begin{array}{l}-0.835^{* * * *} \\
(0.170)\end{array}$ & $\begin{array}{l}0.549^{* * *} \\
(0.147)\end{array}$ \\
\hline Log Windfall (LWF) & $\begin{array}{l}0.142 \\
(0.407)\end{array}$ & $\begin{array}{l}0.787^{* *} \\
(0.343)\end{array}$ & $\begin{array}{l}0.118 \\
(0.382)\end{array}$ & $\begin{array}{l}1.101^{* *} \\
(0.492)\end{array}$ & $\begin{array}{l}0.770^{* *} \\
(0.389)\end{array}$ & $\begin{array}{l}0.165 \\
(0.302)\end{array}$ \\
\hline Flexible Hours (Flex) & $\begin{array}{l}-0.445^{* * * *} \\
(0.173)\end{array}$ & $\begin{array}{l}-0.547 \\
(0.111)\end{array}$ & $\begin{array}{l}-0.386^{* *} \\
(0.161)\end{array}$ & $\begin{array}{l}0.068 \\
(0.139)\end{array}$ & $\begin{array}{l}-0.123 \\
(0.128)\end{array}$ & $\begin{array}{l}-0.205 \\
(0.129)\end{array}$ \\
\hline$($ Flex * LWF) Inter'n & $\begin{array}{l}0.138^{* *} \\
(0.055)\end{array}$ & $\begin{array}{l}0.012 \\
(0.034)\end{array}$ & $\begin{array}{l}0.125^{* *} \\
(0.056)\end{array}$ & $\begin{array}{l}-0.028 \\
(0.043)\end{array}$ & $\begin{array}{l}0.020 \\
(0.037)\end{array}$ & $\begin{array}{l}0.072 \\
0.045\end{array}$ \\
\hline $\begin{array}{l}\text { Log Pseudolik. } \\
\mathrm{N}^{*} \mathrm{~S} \text { (spells) } \\
\mathrm{N} \text { (individuals) }\end{array}$ & $\begin{array}{l}-930.523 \\
1886 \\
880\end{array}$ & $\begin{array}{l}-3513.079 \\
6630 \\
2790\end{array}$ & $\begin{array}{l}-1359.321 \\
2865 \\
1257\end{array}$ & $\begin{array}{l}-2307.101 \\
4321 \\
1722\end{array}$ & $\begin{array}{l}-2473.244 \\
4743 \\
2188\end{array}$ & $\begin{array}{l}-1957.831 \\
3773 \\
1764\end{array}$ \\
\hline
\end{tabular}

Controls: age,age ${ }^{2}$,education,education ${ }^{2}, 13$ industry dummies, 4 family situation dummies, working hours, part-time dummy Significance levels: $10 \%\left({ }^{*}\right), 5 \%\left({ }^{* *}\right), 1 \%\left({ }^{* *}\right)$ 
The results in table 6 provide strong evidence that the second effect dominates: the population is split three times: the two panels on the right give the estimates for childless individuals and for parents, the middle two panels for women and men whereas the left two panels compare mothers to men and childless women. Note that we here focus only on dependent children, such that parents with grown-up children are here categorised as childless. The change in preferences after a wealth shock can be assessed by the interaction term of flexible working hours and the windfall. For a large windfall the coefficient on flexible working hours is shown to change significantly but for certain groups only: for mothers, less strongly for the group of all women and not significantly for parents (including men) and men. Given ample evidence that the majority of childcare is still carried out by mothers this supports the idea that the worker engaging in childcare is the key factor in determining the reduced importance of flexible working hours after a wealth shock.

\subsection{Latent preferences for employer pension contributions}

Around two-thirds of the employment spells $(72 \%)$ in our sample are at employers who run a private pension scheme. Why might preferences regarding this benefit change as a result of the wealth shock? If individuals who win a large windfall gain are less focused on the immediate material needs and more likely to consider long-term perspectives, we may expect an increased importance of this job characteristic in workers' transition decisions.

Table 7: Job leaving as a function of wage, windfalls, employer pension contributions and an interaction term.

The two columns compare coefficients for men and women. See the footnote for the numerous controls included in the regressions. Dependent variable: hazard rate of voluntary job leaving

\begin{tabular}{ll|ll}
\hline & Sample & Women & Men \\
& $\hat{\beta}$ & $\hat{\beta}$ & $\hat{\beta}$ \\
\hline Log Wage & $-0.587^{* * *}$ & $-0.644^{* * *}$ & $-0.640^{* * *}$ \\
& $(0.084)$ & $(0.120)$ & $(0.125)$ \\
Log Windfall (LWF) & $0.102^{* * *}$ & $0.065^{*}$ & $0.138^{* * *}$ \\
& $(0.025)$ & $(0.033)$ & $(0.037)$ \\
Employer Pension Contributions (Pension) & $-0.579^{* * *}$ & $-0.592^{* * *}$ & $-0.488^{* * *}$ \\
& $(0.087)$ & $(0.122)$ & $(0.126)$ \\
(LWF * Pension) Interaction & $-0.056^{* *}$ & -0.030 & $-0.086^{* *}$ \\
& $(0.028)$ & $(0.037)$ & $(0.041)$ \\
\hline Log Pseudolik. & -5904.664 & -2874.462 & -3007.754 \\
N*S (spells) & 10207 & 5078 & 5129 \\
N (individuals) & 3485 & 1718 & 1767 \\
\hline
\end{tabular}

Controls: age,age ${ }^{2}$,education,education², 13 industry dummies, 4 family situation dummies, working hours, part-time dummy Significance levels: $10 \%\left({ }^{*}\right), 5 \%\left(^{* *}\right), 1 \%\left({ }^{* * *}\right)$

The results in table 7 indicate a significant increase in the importance of employers' pension contributions after a wealth shock. When we split the population by gender we find that this effect is driven by male workers. 
How can we interpret this finding? Employer pension contributions can be described as forced savings: A part of workers' earnings is saved for the period after retirement. As workers become more wealthy, this type of arrangement may become more interesting - in particular for those individuals who manage their spending habits less well. This might fit with evidence showing that women are more risk-averse. However, differential savings behaviour may also be the result of time-inconsistent preferences such that men would benefit from the commitment device of forced savings and may show a stronger revealed preference for employer pension contributions $^{11}$.

\section{Concluding remarks}

Using British panel data it has been found that the degree to which wealth influences mobility decisions depends on the degree of job satisfaction individuals have in a particular job. The way in which the labour market distributes utility may depend importantly not only on human capital and luck (as models of the labour market focussing on productivity and frictions imply) but also on non-human capital. The basic finding should be relevant to a number of researchers interested in the interactions between inequality, unearned income and subjective wellbeing in the labour market. It also holds lessons for managers who might be confronted with workers whose high motivation to work may be related to the monetary dimension of their job and thus susceptible to decrease over time as workers accumulate wealth. Whilst the current paper focuses on wealth shocks, further research is called for regarding the rôle of job quality in mobility decisions in a model allowing for wealth accumulation.

Different potential HRM responses have been outlined here. Behavioural changes in preferences over job characteristics were found to be a function not only of the absolute size of windfalls but of windfalls relative to current income. For a given windfall, individuals with lower incomes will thus be more strongly influenced by the arguments advanced here. Consistent with the efficiency wage literature this underlines the strong importance of earnings on job mobility decisions and provides a first potential managerial response.

Whilst subjective job satisfaction is known to be related to objective working conditions in numerous ways, the shift in preferences for job satisfaction was found to go hand in hand with a shift in preferences for two objective job characteristics: whether an employer offers flexible working arrangements and whether an employer participates in an employer pension scheme. We have seen how changing wealth levels impact job demands by workers and considered potential HRM responses: Wealthier workers are less interested in flexible working arrangements and more interested in employer pension contributions.

\section{References}

Abbring, J., \& van den Berg, G. (2007). The Unobserved Heterogeneity Distribution in Duration Analysis. Biometrika, 94, 87-99.

Ai, C., \& Norton, E. (2003), Interaction Terms in Logit and Probit Models. Economics Letters, 80, 123-129.

11 See Sunden and Surette (1998) for a US perspective on gender differences in savings. 
Barrick, M., \& Mount, M. (1996). Effects of Impression Management and Self- deception on the Predictive Validity of Personality Constructs. Journal of Applied Psychology, 81, 261-272.

Barrick, M., \& Zimmerman, R. (2005). Reducing Voluntary Turnover, Avoidable Turnover Through Selection. Journal of Applied Psychology, 90, 159-166.

Burdett, K.. \& Mortensen, D. (1998). Wage Differentials Employer Size and Unemployment. International Economic Review, 39, 257-273.

Clark, A. (2001). What Really Matters in a Job? Labour Economics, 8, 223-242.

Clark, A., Georgellis, Y., \& Sanfey, P. (1998). Job Satisfaction, Wage changes, and Quits: Evidence from Germany. Research in Labor Economics, 17, 95-121.

Freeman, R. (1978). Job Satisfaction as an Economic Variable. American Economic Review, 68, 135-141.

Gielen, A. (2008). Repeated Job Quits:Stepping Stones or Learning about Quality? IZA Discussion Paper.

Hamermesh, D. (1977). Economic Aspects of Job Satisfaction. Wiley: New York.

Holtom, B., Mitchell, T., Lee, T., \& Eberly, M. (2008). Turnover and Retention Research. The Academy of Management Annals, 2, 231-274.

Houseman, S. (2001). Why Employers Use Flexible Staffing Arrangements: Evidence from an Establishment Survey. Industrial and Labor Relations Review, 55, 149-170.

Hwang, H., Mortensen, D. T., \& Reed, W. R. (1998). Hedonic Wages and Labor Market Search. Journal of Labor Economics, 16, 815-847.

Lee, T., Gerhart, B., Weller, I., \& Trevor, C. (2008). Understanding Voluntary Turnover: Path-specific Job Satisfaction Effects and the Importance of Unsolicited Job Offers. Academy of Management Journal, 51, 651-671.

Lee, T., \& Mitchell, T. (1994). An Alternative Approach: The Unfolding Model of Voluntary Employee Turnover. Academy of Management Review, 19, 51-89.

March, J., \& Simon, H. (1958). Organizations. New York: John Wiley.

Postel-Vinay, F., \& Robin, J.-M. (2002). Equilibrium Wage Dispersion with Worker and Employer Heterogeneity. Econometrica, 70, 2295-2350.

Rosen, S. (1986). The Theory of Equalizing Differentials. In O. Ashenfelter \& R. Layard (Eds.), Handbook of Labor Economics. Vol. 1 (pp. 641-692). Elsevier.

Sunden, A., \& Surette, B. (1998). Gender Differences in the Allocation of Assets in Retirement Savings Plans. American Economic Review, 88, 207-211.

van den Berg, G. (2001). Duration Models: Specification, Identification, and Multiple Durations. In James J Heckman \& Edward Leamer (Eds.), Handbook of Econometrics. Vol. 5. Elsevier.

Wanous, J., Reichers, A., \& Hudy, M. (1997). Overall Job Satisfaction: How Good Are Single-Item Measures? Journal of Applied Psychology, 82, 247-252.

Wilson, P. (1989). Scheduling Costs and the Value of Travel Time. Urban Studies, 26, 356-366. 